\title{
The New Three-dimensional Ultrasound Modes allow a Better Polycystic Ovary Syndrome Ultrasound Diagnosis beyond the Rotterdam Criteria
}

\author{
${ }^{1}$ Francisco Raga, ${ }^{2}$ Francisco Bonilla Jr, ${ }^{3}$ Oscar Caballero, ${ }^{4}$ Juan Carlos Castillo, ${ }^{5}$ Fernando Bonilla-Musoles
}

\begin{abstract}
Polycystic ovary syndrome (PCOS) is a complex endocrine condition affecting reproductive-aged women. The exact etiology of this condition remains elusive and the definition of the syndrome has undergone several revisions in which ovarian morphology plays a central role. This review describes several and modern three-dimensional (3D) ultrasound modes including: HDlive ${ }^{\mathrm{TM}}$, virtual organ computer-aided analysis (VOCAL), inversion mode, Radiance System Architecture ${ }^{\mathrm{TM}}$, for the study of PCOS-related ovarian morphology. This state-of-the-art technology should be employed-when available, in the evaluation of PCOS-related ovarian morphology.
\end{abstract}

Keywords: Ovary, PCOS diagnosis, Reproductive endocrinology, Rotterdam criteria, Three-dimensional/HDlive/ radiance system architecture ultrasonography.

How to cite this article: Raga F, Bonilla $\mathrm{F} \mathrm{Jr}$, Caballero O, Castillo JC, Bonilla-Musoles F. The New Three-dimensional Ultrasound Modes allow a Better Polycystic Ovary Syndrome Ultrasound Diagnosis beyond the Rotterdam Criteria. Donald School J Ultrasound Obstet Gynecol 2015;9(4):434-445.

Source of support: Nil

Conflict of interest: None

\section{INTRODUCTION}

Polycystic ovary syndrome (PCOS) is the most common endocrine disorder in reproductive-aged women, affecting 12 to $21 \%,{ }^{1}$ and the second most common cause of women infertility after aging.

Polycystic ovary syndrome is a complex endocrine condition due to its heterogeneity and uncertainty about its etiology. Several research groups have suggested that the origin of PCOS lays within genetics (polygenic) and/or environmental androgen effects in fetal life, and involves the fetal (re)programming of metabolic/

\footnotetext{
${ }^{1-3}$ Professor, ${ }^{4}$ Researcher, ${ }^{5}$ Professor and Chairman

1-3,5Department of Obstetrics and Gynecology, School of Medicine, University of Valencia, Valencia, Spain

${ }^{4}$ Assisted Reproduction Unit, Instituto Bernabéu, Alicante, Spain

Corresponding Author: Fernando Bonilla-Musoles, Professor and Chairman, Department of Obstetrics and Gynecology, School of Medicine, University of Valencia, Valencia, Spain, e-mail: profesorbonillamusoles@hotmail.com
}

endocrine axes, especially carbohydrate metabolism and adrenal secretion. ${ }^{2}$

Due to the fact that diagnostic criteria rely on clinical, biological and morphological criteria, the definition has undergone several revisions. ${ }^{3}$

At the National Institutes of Health (NIH) consensus conference held in $1990^{4}$, PCOS was defined as:

- Chronic anovulation with

- Clinical and/or biochemical hyperandrogenism after excluding other mimicking etiologies, such as thyroid or adrenal dysfunction.

In 2003, the Rotterdam consensus of the European Society for Human Reproduction/American Society of Reproductive Medicine (ESHRE/ASRM) ${ }^{5}$ proposed that the diagnosis should include two out of three of the following criteria: $: 5$

- Oligo and/or anovulation

- Clinical and/or biochemical hyperandrogenism

- Polycystic ovaries on ultrasound

Other etiologies must be excluded.

Most recently, in 2009, the Androgen Excess and PCOS (AE-PCOS) Society ${ }^{7,8}$ published a task force report emphasizing that PCOS was primarily a hyperandrogenic disorder and should, therefore, include hyperandrogenism (hirsutism and/or hyperandrogenemia) and ovarian dysfunction (oligoanovulation and/or polycystic ovaries) in the definition; thereby encompassing the Rotterdam ultrasound criteria but requiring hyperandrogenism for the diagnosis.

In 2011, the Amsterdam ESHRE/ASMR-sponsored 3rd PCOS consensus workshop group identified different phenotypes and separated the most classic phenotype, characterized by ovarian dysfunction and polycystic morphology. ${ }^{9}$

Finally, some progress has been made toward reaching unity about the diagnostic criteria with the recommendations of the expert panel following the $\mathrm{NIH}$ evidence-based methodology on PCOS in 2012. ${ }^{10,11}$

\section{CLINICAL CRITERIA}

Oligo/anovulation is usually described in women with menstrual cycles greater than 35 days apart. It is important to remember that even women with regular 
cycles may be anovulatory. Irregular or absent menstrual cycles may lead to subfertility or infertility.

Hyperandrogenism, acne, hypertricosis or hirsutism are characteristic PCOS features. Hirsutism is difficult to assess as most women treat it, so it might not be obvious on examination. Hyperandrogenemia is measured with free testosterone; free androgen index (FAI) or bioavailable testosterone. This hyperandrogenemia, insulin resistance and obesity are pathophysiological features of PCOS.

In 2009, a task force report of the AE-PCOS society for the PCOS, ${ }^{8}$ by using combinations of these criteria, identified four different PCOS phenotypes:

- Hyperandrogenism (clinical or biochemical) and chronic anovulation (H-CA)

- Hyperandrogenism and polycystic ovaries on US but with ovulatory cycles (H-PCO US)

- Chronic anovulation and polycystic ovaries hyperandrogenism (CA-PCO US)

- Hyperandrogenism, chronic anovulation and polycystic ovaries (H-CA-PCO US)

The identification and individualization of specific phenotypes in women having PCOS seems to be justified from the metabolic point of view.

\section{BIOCHEMICAL CRITERIA}

The biochemical recommended testing in adolescents presenting with PCOS-like symptoms are:

- Thyroid stimulating hormone(TSH), FSH, LH, prolactin and $17 \beta$-estradiol (in amenorrheic adolescents).

- Anti-müllerian hormone (AMH) which shows an equal or better performance than antral follicular count (AFC). ${ }^{12,13}$

- Testosterone-total serum concentration as first-line recommendation.

- Free testosterone, also as first-line recommendation

- Free androgen index (T/SHBG × 100)

- Dehydroepiandrosterone sulfate (DHEAS) and androstenedione levels are optional.

- 17-OH progesterone

Once PCOS has been confirmed, fasting and 2-hour glucose tolerance test, fasting insulin and lipid panel should be determined.

\section{ULTRASOUND CRITERIA INCLUDING STATE-OF- THE-ART 3D VISUALIZATION MODES}

\section{Transvaginal Two-dimensional Ultrasound}

For the study of PCOS-associated ovarian morphology (PCOM), the international societies (ESHRE, the European Society of Endocrinology and the AE-PCOS society $)^{5,11}$ recommend the following:

- The use of transvaginal ultrasound including scan frequencies of 7.5 to $8 \mathrm{MHz}$ or more.
- An early follicular phase scan.

- All follicles $\geq 2 \mathrm{~mm}$ should be included in the AFC being measured in the three spatial planes (Fig. 1).

Early comparative studies showed intra and interobserver variations in the two-dimensional (2D) transvaginal $\mathrm{AFC}$ in the general population and a 12 to $13 \%$ rate of underestimation in the exact number of antral follicles present within the ovary, ${ }^{11}$ however, recent studies, using new three-dimensional (3D) US modes, increase this underestimation rate up to 20 to $30 \%$. $^{12-17,22}$

Besides this limitation, and in order to maintain standard criteria for research purposes, 2D transvaginal scan remains as the recommended method for antral follicle count in the general population including PCOS patients, and the count of at least 12 follicles remains the limit to categorize a polycystic appearance ovary. ${ }^{6}$

Herein, we describe several and modern 3D ultrasound modes for the study of PCOS-related ovarian morphology; these new methods are scarcely mentioned on the medical literature since the clinical experience is limited; further, they are sometimes described as 'future techniques'.

\section{Tomographic Ultrasound Image (TUI)}

This software performs millimetric sections within the acquired volumetric image of the ovary in the three spatial planes, and allows the visualization and quantification of all the antral follicles present (Fig. 2).

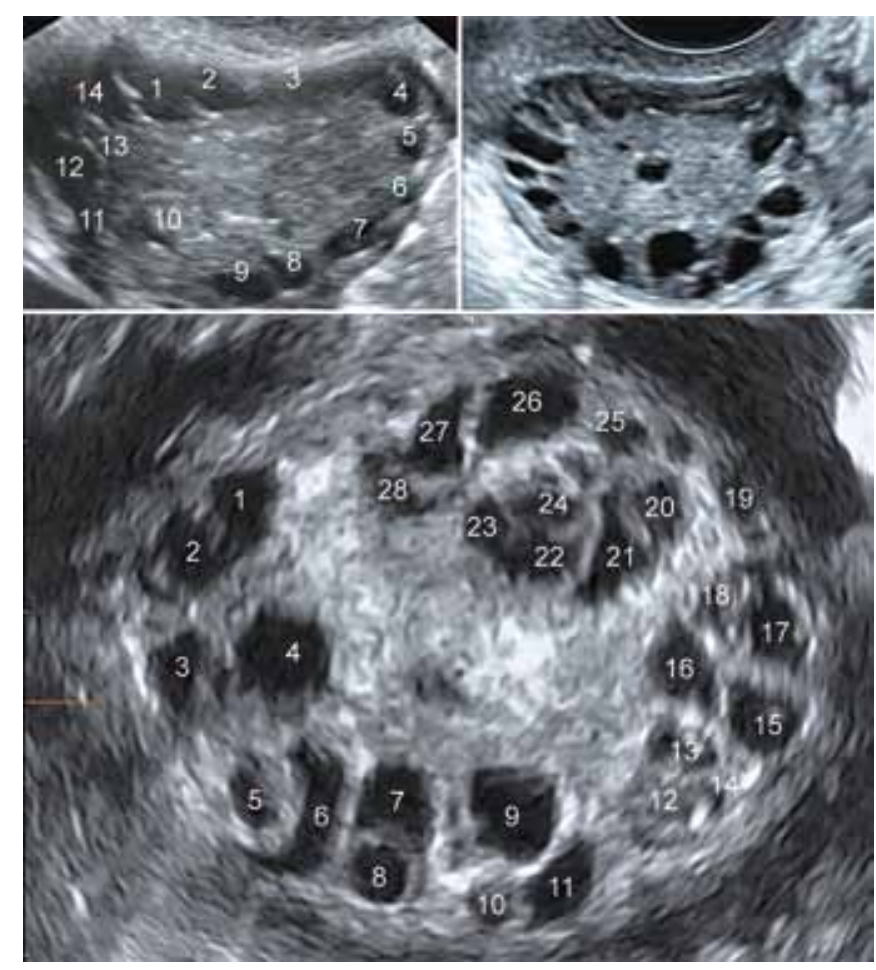

Fig. 1: Transvaginal 2D scan using a $7.5 \mathrm{MHz}$ probe in a PCOS patient: antral follicles are measured and numbered in this image in two different spatial planes 


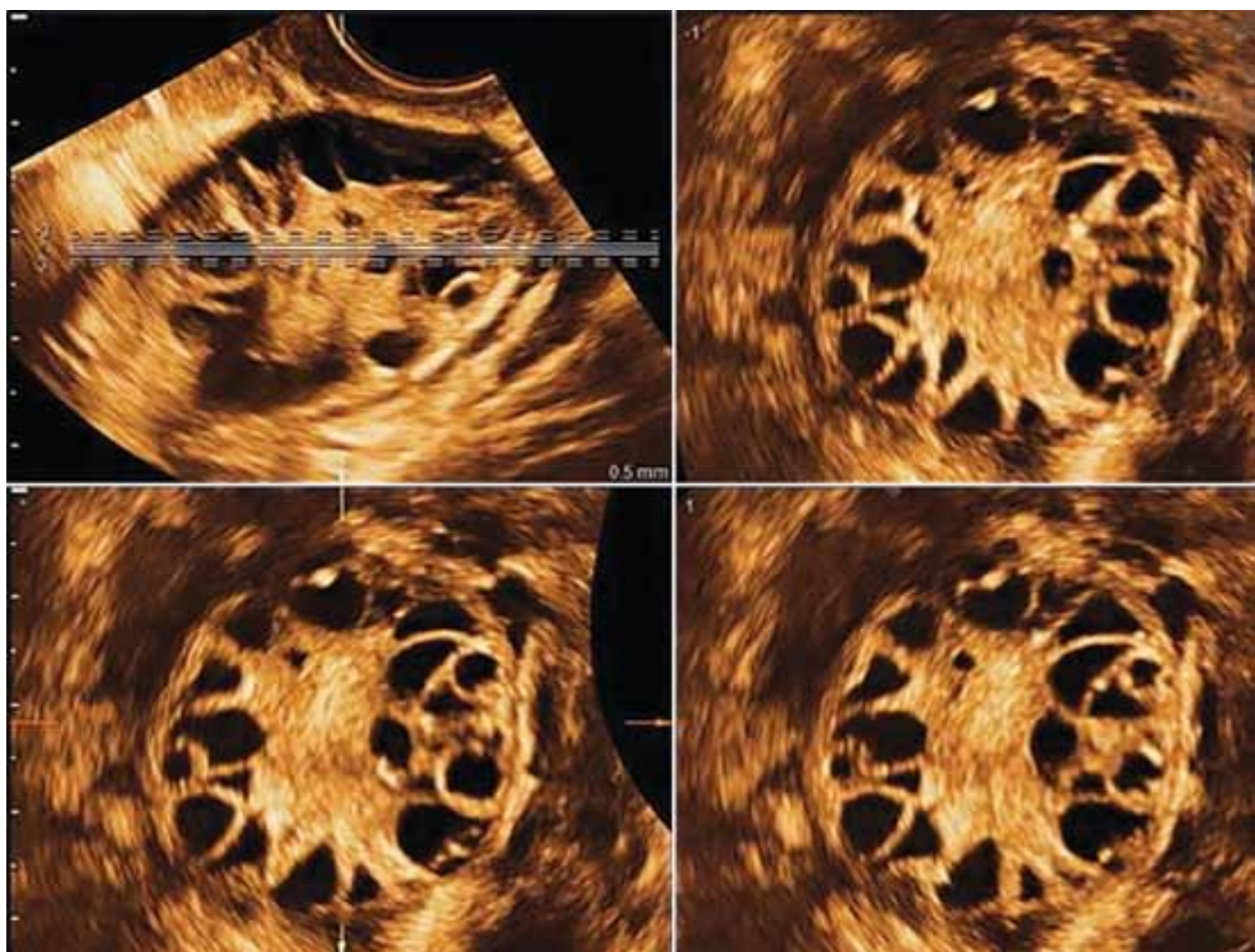

Fig. 2: Tomographic ultrasound image (TUI) in a transversal plane of a polycystic ovary (Voluson E8 GE ${ }^{\circledR}$ ). The AF can be clearly seen in separated sections. The amplitude of the sections can be selected at convenience

\section{Inversion Mode}

This 3D US software converts econegative structures into ecopositive and vice versa, somehow similar to the old movie films used in the early days of cinema which used black and white (positive) or inverted (negative) images. In this ecographic mode, we can see the ovaries in 'negative'. Since the antrum space within the follicle is full of fluid-econegative-this software turns them into ecopositive. Moreover, the software eliminates the surrounding ovarian tissue, hence, the antral follicles appear in white color [or sepia in the current case (Fig. 3)] thus making AF counting easier.

This new rendering technique requires good image quality to identify the follicular margin, ${ }^{18,19,21}$ however, cannot accurately assess AF of less than 5 to $6 \mathrm{~mm}^{20}$ (Fig. 3).

It is quite simple to obtain this type of images, it only requires a 3D sweep on the region of interest and then selecting the inversion mode within the software panel, due to its simplicity this software is strongly recommended for clinical practice. ${ }^{21}$

\section{Virtual Organ Computer-aided Analysis (VOCAL)}

The sonographer performs several sections of the ovary, then the software integrates these sections and automatically calculates the volume of the region under study. This 3D US mode is ideal for ovarian volumetric calculation $^{21}$ (Figs 4 and 5).

\section{Automatic Volume Calculation (AVC)}

The software of this 3D US mode delineates and designates in different colors each AF facilitating enormously its counting (Figs 6 and 7). At the same time, evaluates three diameters and the total volume of each follicle, showing those which are more developed. ${ }^{18-21}$

\section{Three-dimensional Digital Doppler Angiography}

This 3D US mode shows the whole ovarian or follicular vasculature depicted in 3D US Doppler color or energy. The quality of the image is superior to those obtained with 2D transvaginal Doppler (Fig. 8).

\section{Three-dimensional HDlive and Radiance System Architecture}

Three-dimensional ultrasound has been used during the past 20 years by many investigators due to its excellence in showing ovarian images. ${ }^{11,14-25}$ Three-dimensional ultrasound imaging (Figs 9 and 10) has potential advantages over standard 2D US:

- Reduced intra and interobserver variability ${ }^{16,18-21,24,25}$

- Shorter time for US procedures ${ }^{18,24,25}$

- Post-processing imaging analysis ${ }^{20}$

- The use of fully automated 3D technology is an exciting prospect, with much better results in counting AF than 2D. 


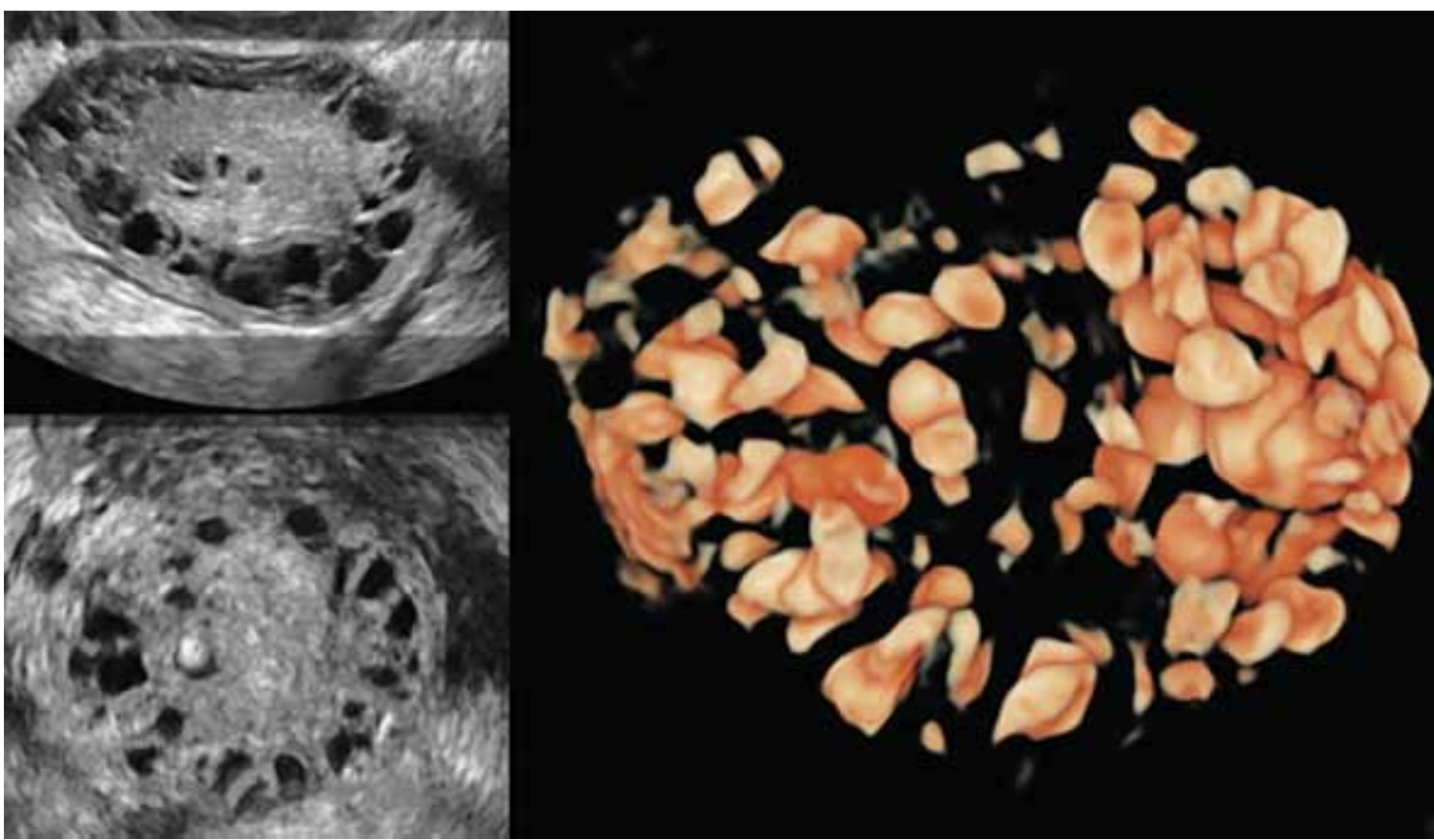

Fig. 3: Comparative imaging of an ovary displaying PCOM: Left-2D ultrasound scan, right-3D ultrasound scan using the inversion mode (Voluson E8 $\mathrm{GE}^{\circledR}$ )

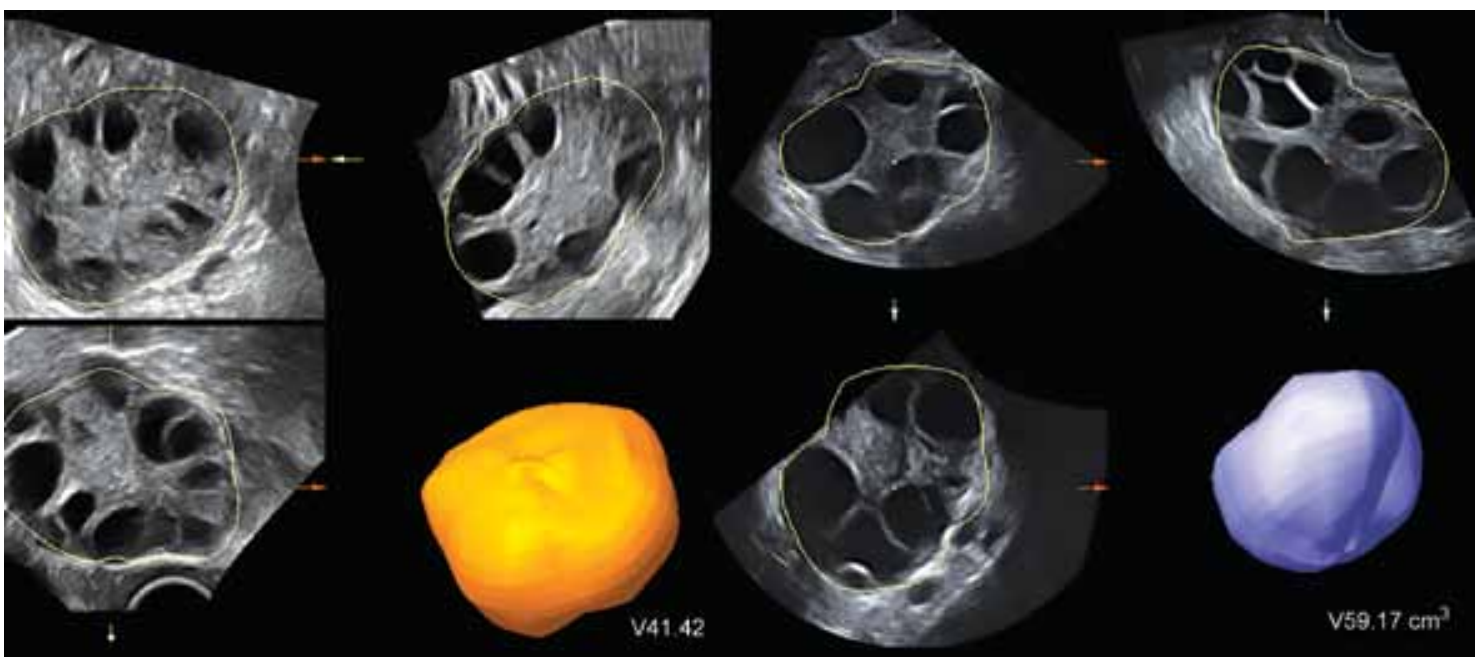

Fig. 4: Virtual organ computer-aided analysis (Voluson $\mathrm{E} 8 \mathrm{GE}^{\circledR}$ ) measurement of the ovarian volume in two cases of PCOS. The software automatically calculates the ovarian volume
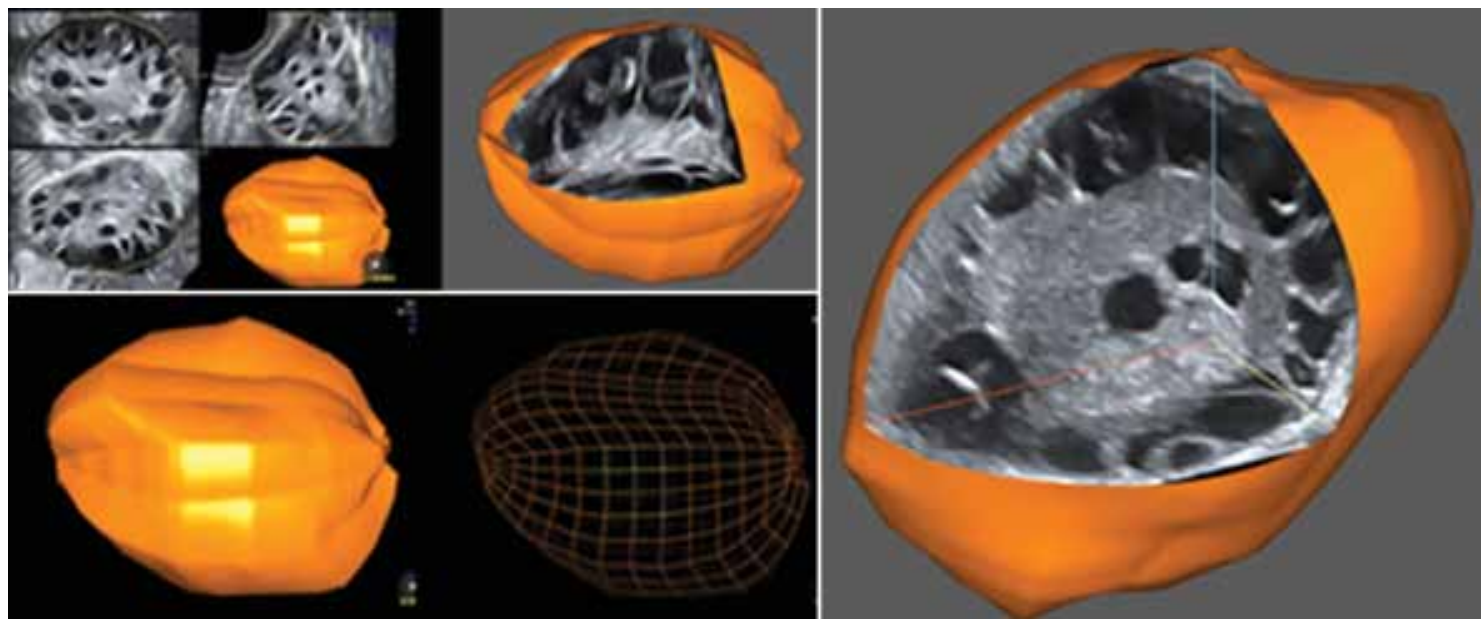

Fig. 5: Volume calculation of the ovary using VOCAL and NICHE mode (Voluson E8 GE ${ }^{\circledR}$ ). This mode shows the ovarian surface in orange, the medulla in gray and numerous sorrounding AF, of similar size, on the periphery 


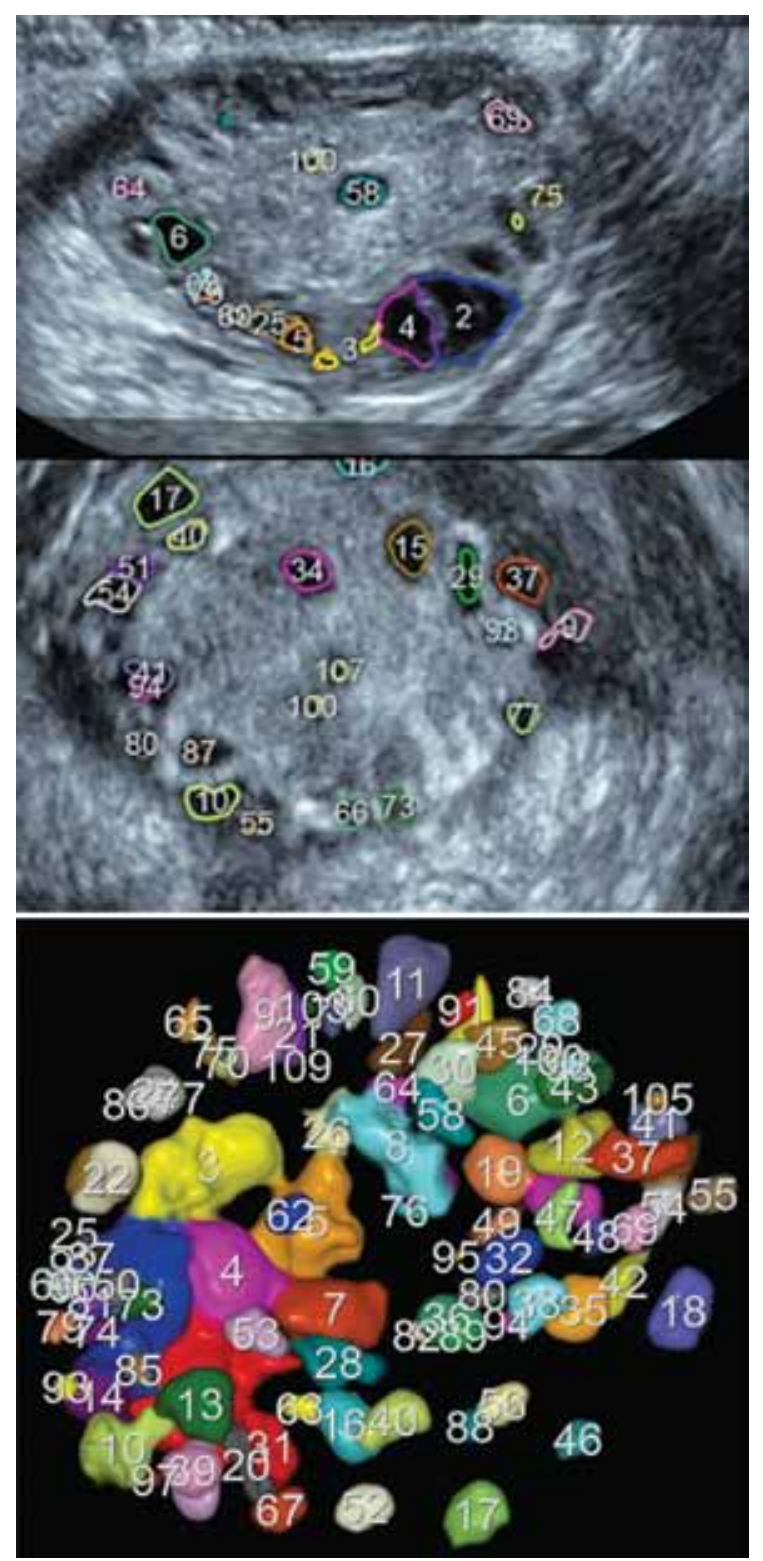

Fig. 6: Automatic volume calculation (Voluson E8 GE ${ }^{\circledR}$ ) in a PCOM. The software shows each follicle in a different color and calculates the three diameters and volume automatically
Radiance System Architecture (Voluson E10 GE®), a new software to depict AF and ovarian cortex, increases much more the image quality (Figs 11 to 13).

However, 3D US and all these new modes cannot be recommended for routine clinical practice until:

- Additional data on reliability are available.

- The high cost of 3D imaging equipments may be reduced.

- Nevertheless, manual follicle counts from stored 3D data currently provide the optimal method of AFC assessment and would minimize many of the practical pitfalls of conventional 2D US evaluation.

- Nonetheless, it was agreed that the use of real-time 2D US imaging is adequate for measurement and counting of AF in routine clinical practice. ${ }^{26,27}$

\section{POLYCYSTIC OVARIES AND ULTRASONOGRAPHIC EVALUATION}

With the advent of ultrasonography, follicle excess has become the main aspect of polycystic ovarian morphology $(\mathrm{PCOM})^{1}$ as well as the main aspect of PCOS diagnosis.

Since 2003 Rotterdam criteria, ${ }^{5}$ the following transvaginal US criteria were recommended ${ }^{6}$ and most clinician have been using:

- A threshold of 12 follicles, measuring 2 to $10 \mathrm{~mm}$ in diameter per whole ovary

- And an ovarian volume (OV) of $\geq 10 \mathrm{ml}$, But that now seems obsolete. ${ }^{28}$

\section{STATE-OF-THE-ART: NEW CRITERIA AND US MODES}

We remark newly 3D US criteria that should be used and the modern 3D US modes introduced that-whenever possible-should be employed.

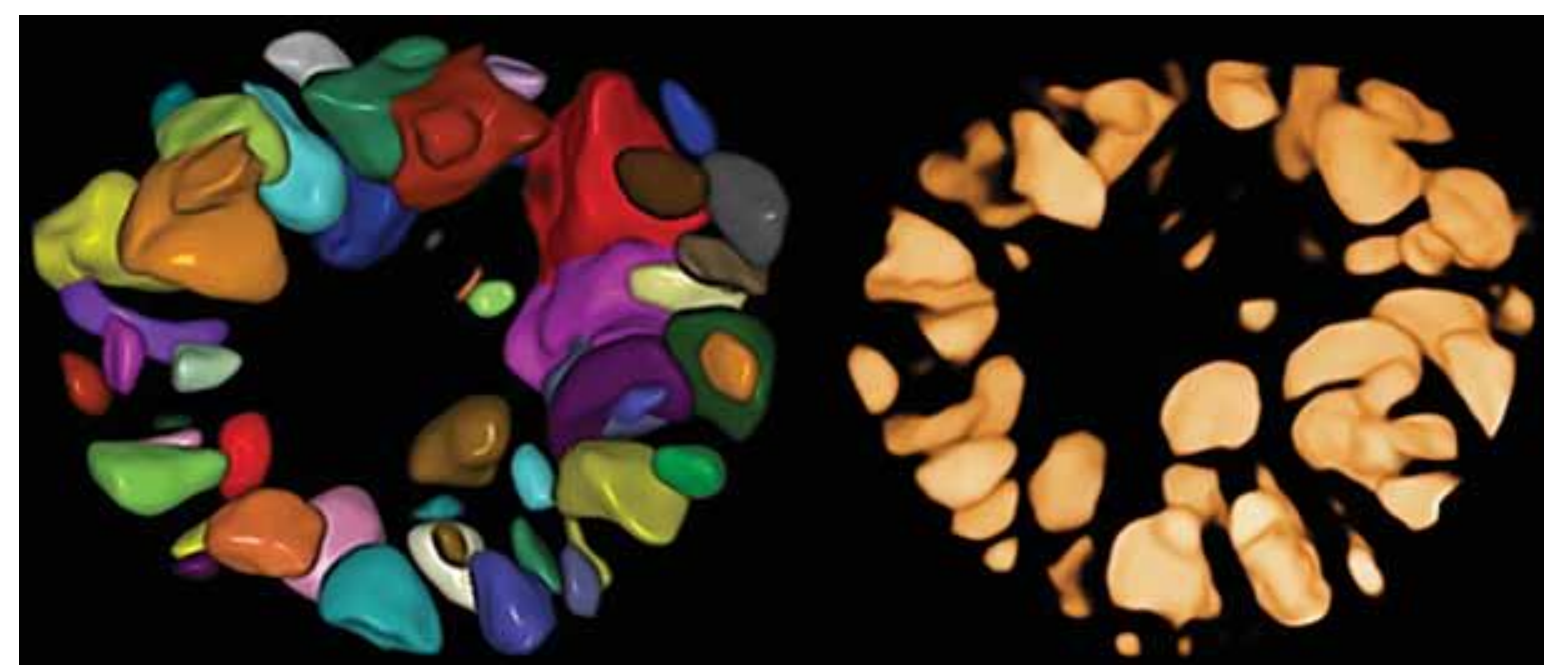

Fig. 7: Comparison between AVC (left) and inversion mode (right) for AF count 


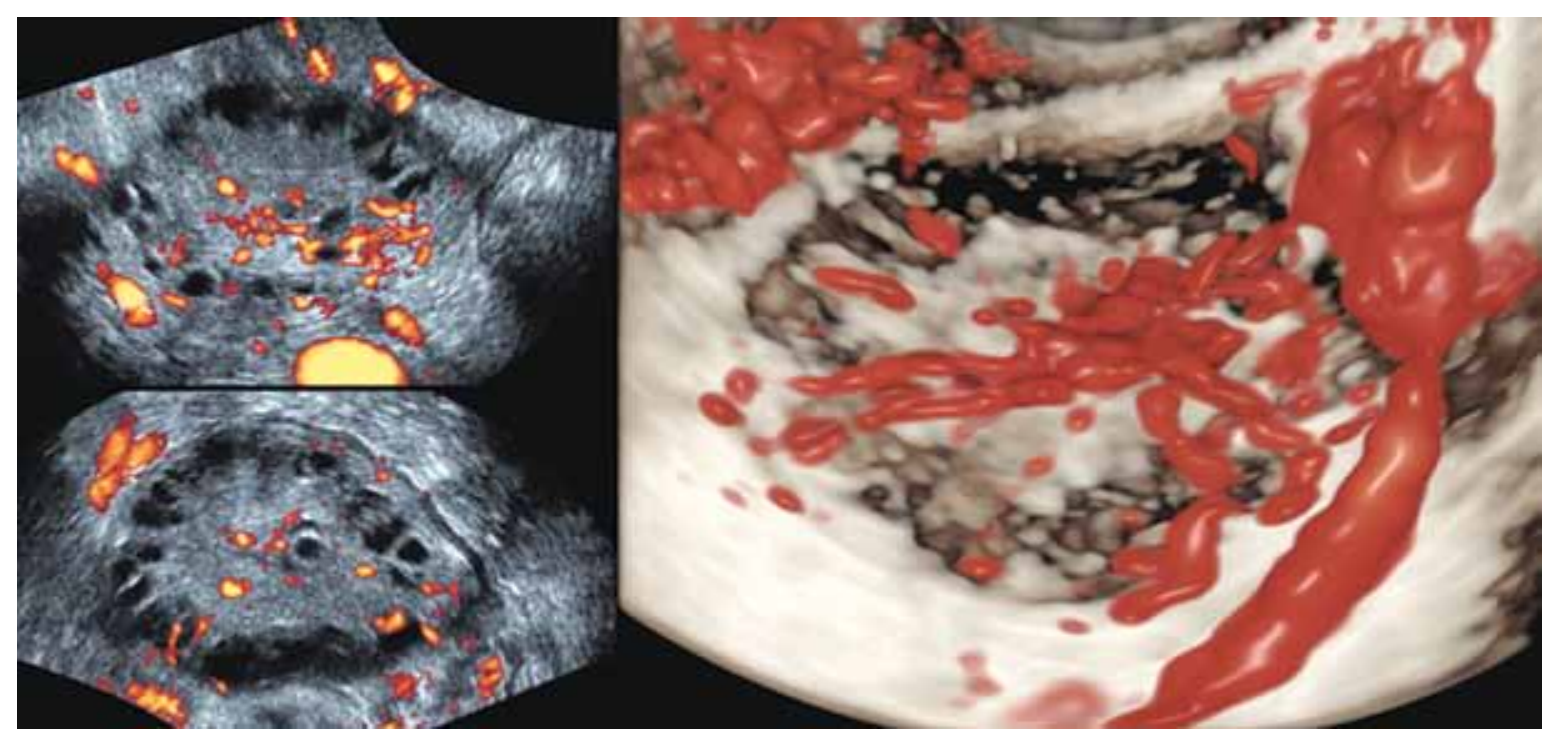

Fig. 8: Three-dimensional US color Doppler angiography of the ovary in a case of PCOS (Voluson E10 GE ${ }^{\circledR}$ ). Compare the quality of the images depicted within 3D angiography (right) to 2D transvaginal Doppler energy (left)

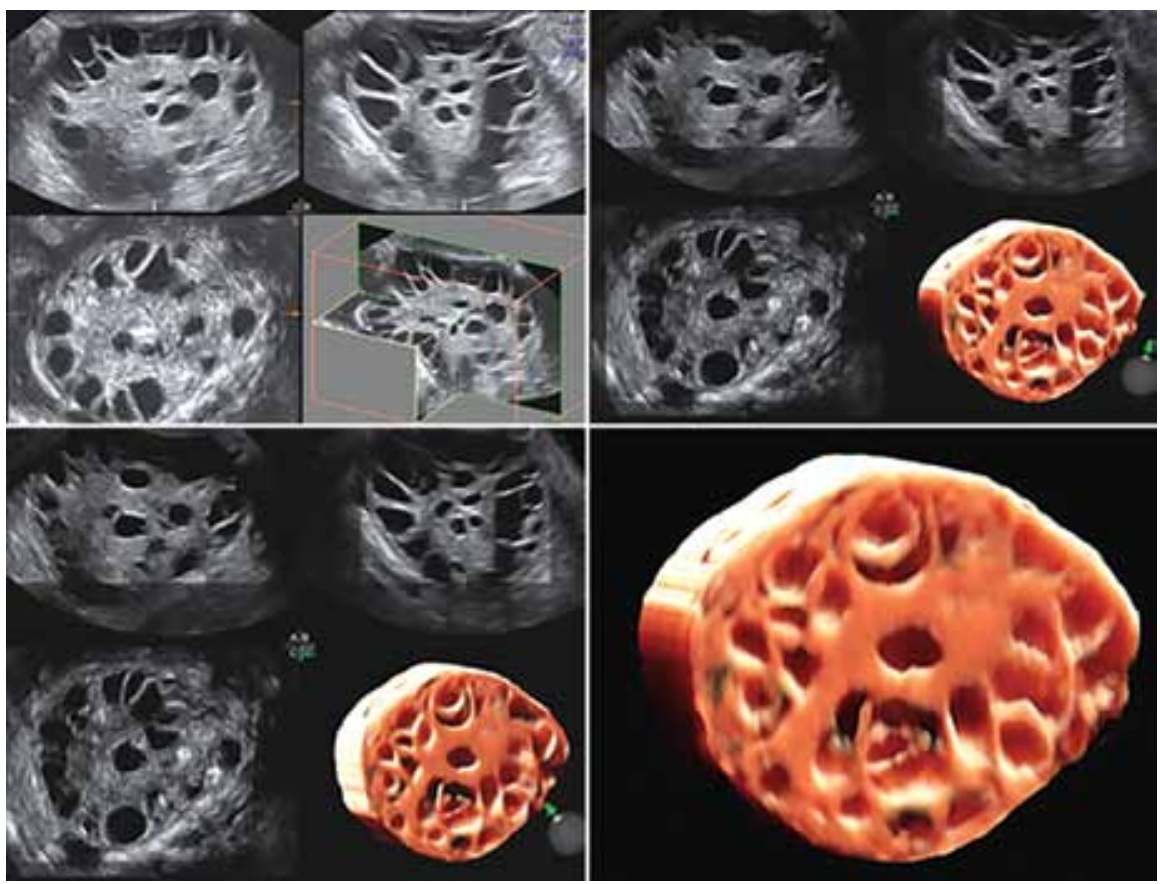

Fig. 9: Polycystic ovarian morphology 3D US HDlive is an excellent mode to increase the image quality

\section{POLYCYSTIC OVARIAN MORPHOLOGY}

Polycystic ovarian morphology designates the morphologic appearance of the polycystic ovaries under transvaginal sonographic view. Herein, we have described specific morphologic appearance in PCOS using advanced ultrasonographic software, this morphologic descriptions strictly correlates to current diagnostic criteria, ${ }^{30}$ and moreover, is-in our opinion-more specific than the description given in Rotterdam criteria: ${ }^{5,29}$

- Polycystic ovaries always show an ovarian surfacethe albuginea-which is very thin and highly bright (Figs 11 to 13), unfortunately little diagnostic value is given to this feature.
- The follicular distribution is located, almost in all cases, surrounding the ovarian cortex (Figs 1, 2, 4 to $7,10,13$ and 16).

Although this peripheral distribution is a typical feature of PCOM (in our opinion of outstanding interest for diagnosis), some previous considerations should remain:

- It is not always present in both ovaries, can be unilateral.

- Can be diffuse occupying the whole ovary.

- The size of the AF ranges between 2 and $9 \mathrm{~mm}$, and is frequently similar in both ovaries (Figs 5 to 11).

- All these morphologic characteristics are usually present in both ovaries providing that the etiologic 


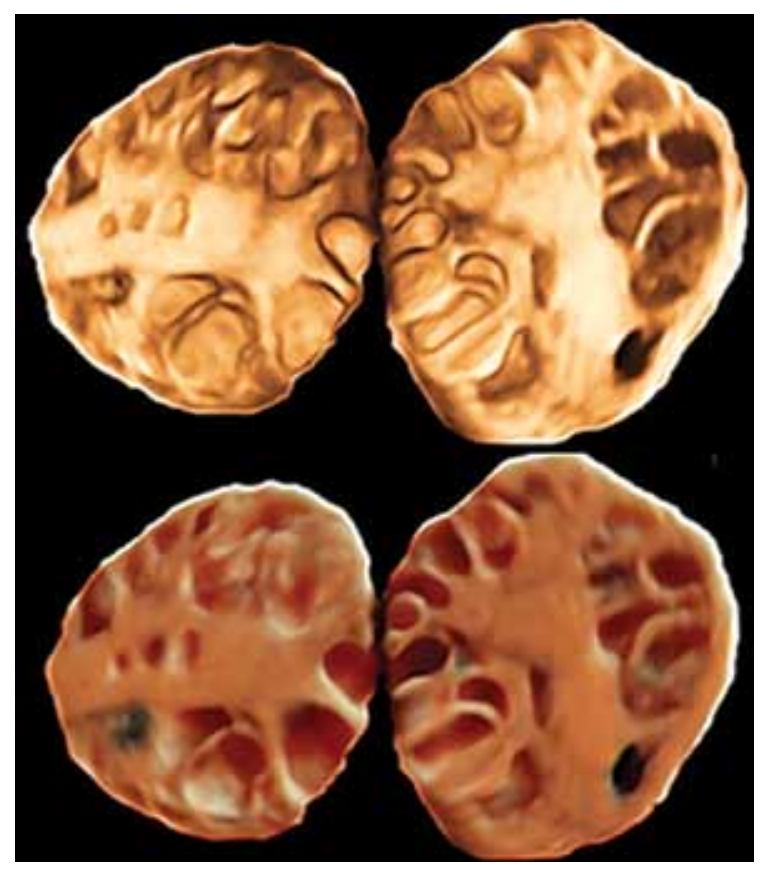

Fig. 10: Comparison of conventional 3D US (above) vs 3D HDlive (below) images of PCOS. HDlive increases the quality imaging view of 3D US
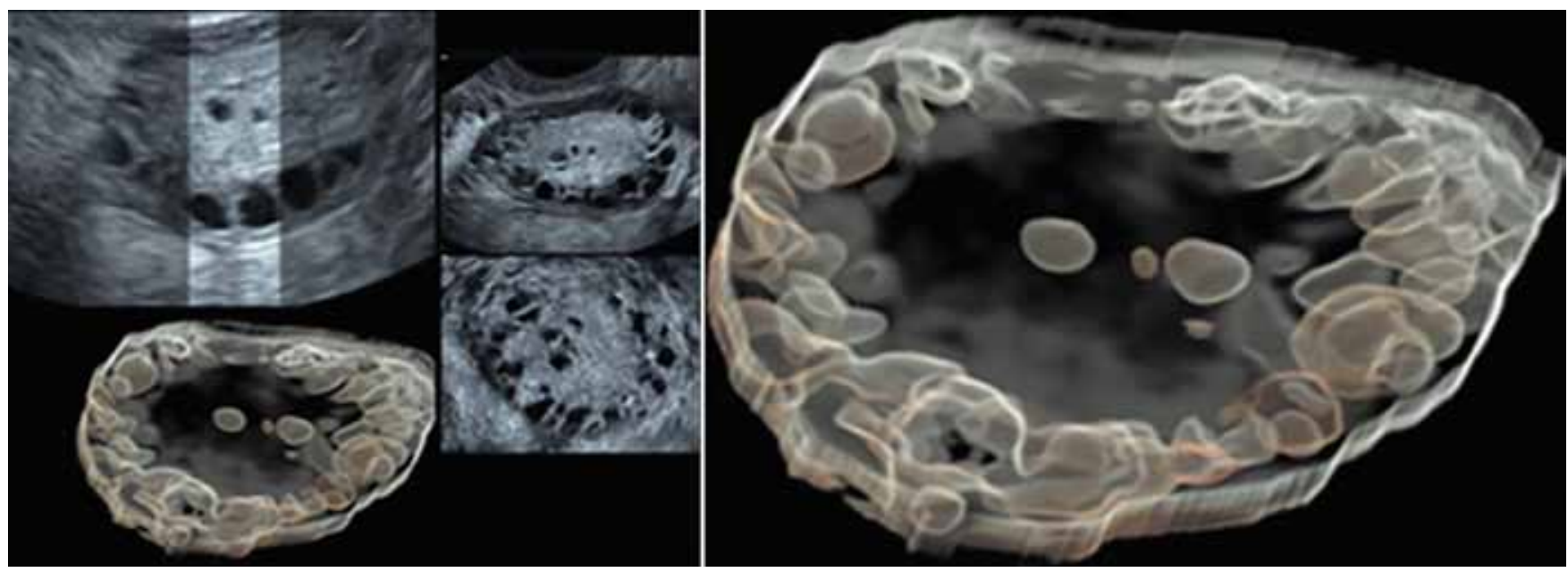

Fig. 11: Radiance system architecture (Voluson $\mathrm{E} 10 \mathrm{GE}^{\circledR}$ ) of an ovary with PCOS (right), compared to $2 \mathrm{D}$ US (left). This is the most advanced 3D US mode which allows a wonderful view of the isolated antral follicles and the ovarian tunica albuginea
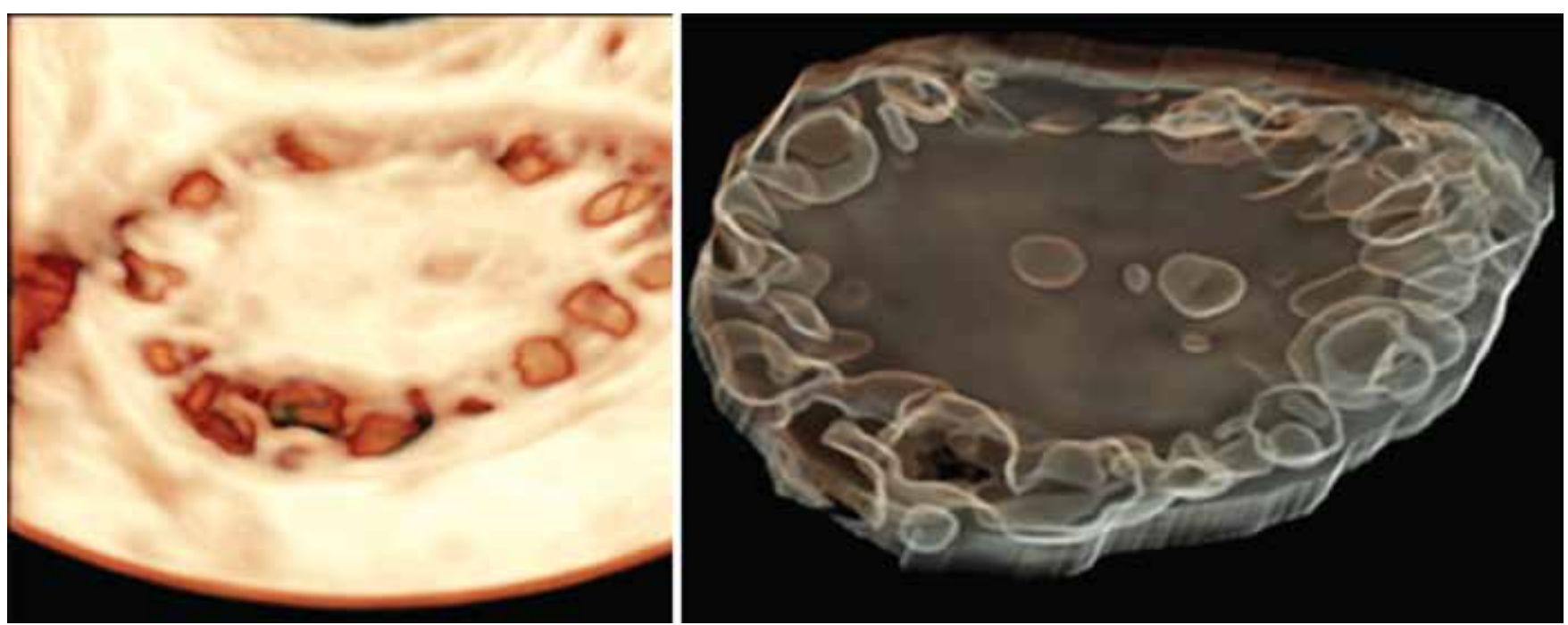

Fig. 12: A PCOM depicted using 3D HDlive (left) vs Radiance System Architecture (right) 


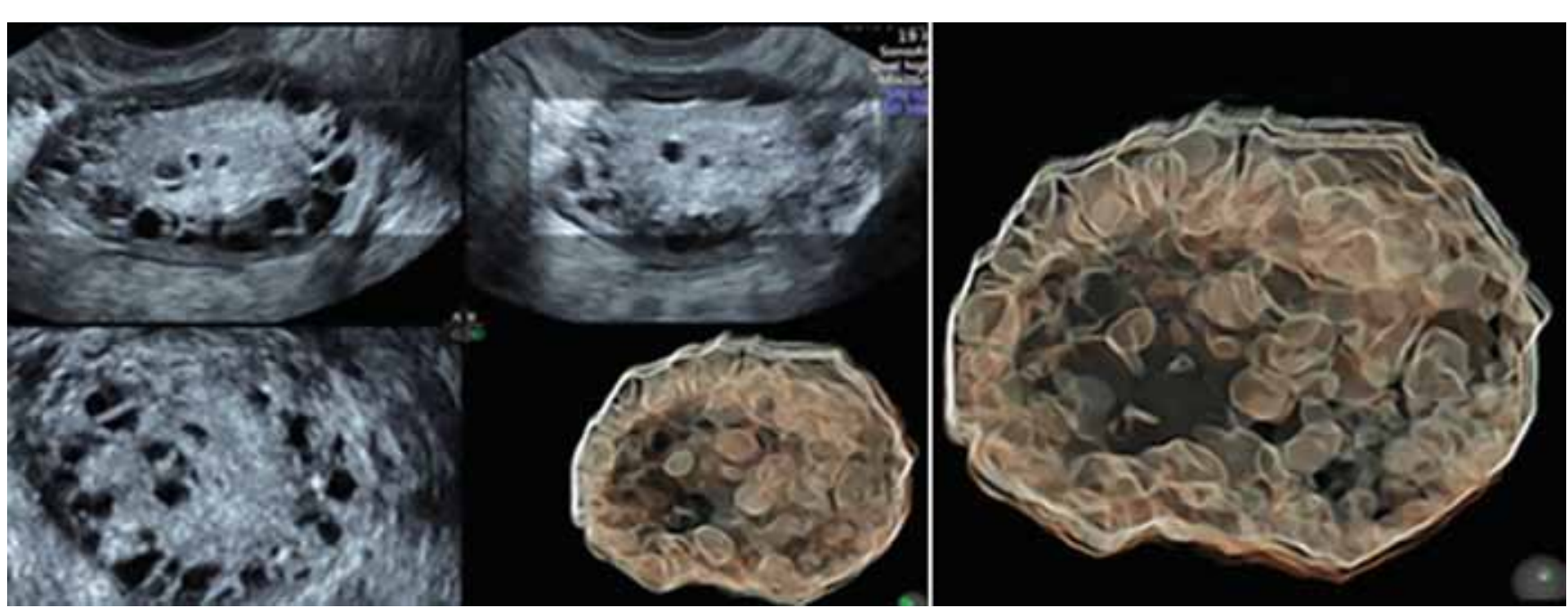

Fig. 13: Polycystic ovary syndrome-related ovarian morphology image using Radiance System Architecture. Each AF is clearly depicted with much better resolution than with standard 2D US

Several studies in the last two decades have addressed comparatively 2D vs 3D scan accuracy, and the results clearly showed than $2 \mathrm{D}$ underestimate in 12 to $13 \%$ the exact number of AF available, ${ }^{11,21}$ moreover, recent studies report even higher differences of up to 25 to $30 \%$ of underestimation. ${ }^{14-16}$ Modern 3D ultrasonographic modes like AVC and inverse mode seem to be more accurate when measuring AFC; ${ }^{18}$ likewise, VOCAL appear to be very important for volumetry. ${ }^{16,17,21,22}$

Recent publications focused on PCOS patients showed a mean number of AFC of 19 to 26 follicles. ${ }^{12,13,28}$ This situation has arisen from the marked improvements in the level of spatial resolution afforded by newer ultrasound scanners.

Ovarian volume or area (OA) were also included as mandatory diagnostic criteria by ESHRE.

Ovarian volume appears to be a good surrogate marker of PCOM although, when compared with FNPO, it has less sensibility for discriminating between patients with PCOM and controls in all the studies comparing both parameters. As the AFC declines progressively over time, ${ }^{32-34}$ it provides a more useful clinical marker of ovarian responsiveness than OV.

Large-scale studies over the three last decades have shown that $\mathrm{OV}$ is inversely correlated with age (climacteric and menopause) $^{10}$ intake of anovulatory pills, GnRH-agonist and antagonist ${ }^{21}$ and diabetes but positively correlated to puberty (beginning of hormonal secretion) and normal ovarian cycles. ${ }^{24,26,27,31,35,36}$

Two-dimensional transvaginal scan measures two planes in order to obtain the ovarian area, and three planes for obtaining the volume of the ovary after the application of the ellipsoid formula $(v=4 / 3 \pi \mathrm{LD}+\mathrm{APD}+$ $\mathrm{TD} / 2$ ); however, there is a high probability of interobserver variations.
Based on all the previous considerations, our critical review shows that $\mathrm{OV}$ has less diagnostic potential for PCOM compared to AFC. The usefulness of OV compared to follicle excess remains unclear.

European Society for human reproduction and latter studies suggested maintaining the threshold for increased $\mathrm{OV} \geq 10 \mathrm{ml}$. By using AVC and VOCAL, ${ }^{14-17,21}$ the measurement of the ovarian volumetry can be more exactly obtained (Figs 3 to 6 and 8). If such technology is not available, then $\mathrm{OV}$ is recommend rather than FNPO for the diagnosis in routine daily practice but not for research studies that require the precise full characterization of PCOM in each patient.

\section{The Medulla of the Ovary}

Surprisingly, Rotterdam criteria do not consider the characteristics of the ovarian medulla as relevant for diagnosis. ${ }^{5}$

Decades ago, specific characteristics of this ovarian zone for PCOS patients were described, including an increased vascularization, thickness and echogenicity. Some authors considered it as an additional feature of PCOS (Figs 14 and 15). ${ }^{11,21}$

This review emphasizes that both ultrasonographic features: thickness of the medulla and antral follicles distribution and count should be included for a correct description of PCOM. However, regarding the thickness of the ovarian medulla, there was a lack of consensus on quantitative measure for standardization. ${ }^{28}$ The ratio of ovarian stroma to total ovarian size may be a good criterion for the diagnosis of PCOS, with a cut-off value of 0.32 and has been suggested that its size is associated with more hyperandrogenemia. ${ }^{37}$

Nowadays, a new way to quantify the thickness of the medulla is to use the double VOCAL technique or combining it with the niche mode. The software quantifies at the same time the medullar volume as well as the total OV (Fig. 15). 

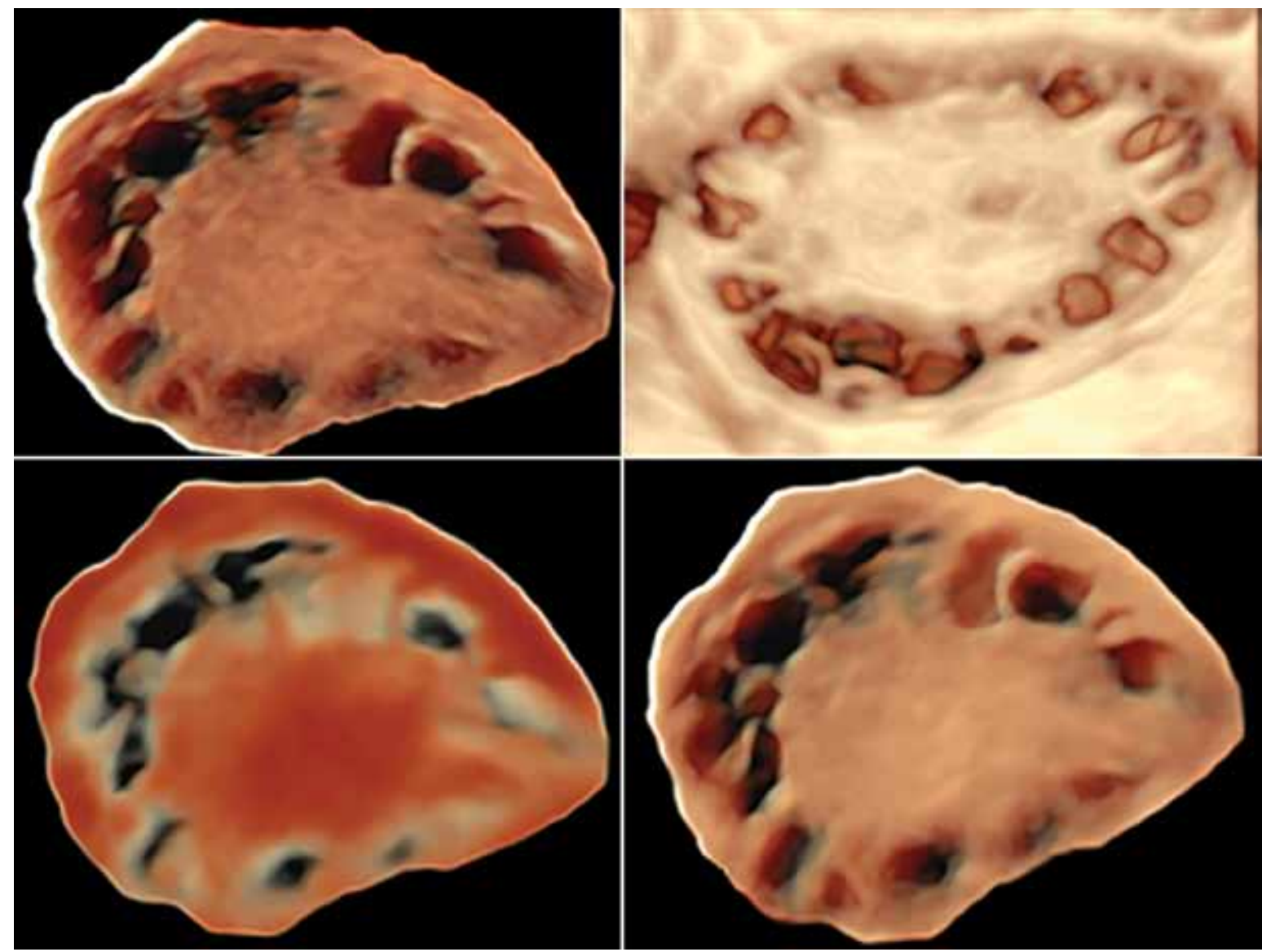

Fig. 14: Left: Polycystic ovarian morphology using HDlive without (upper left) and with (bottom left) maximum transparency. Note the increased thickness of the medulla and the AF located peripherally in the ovarian cortex

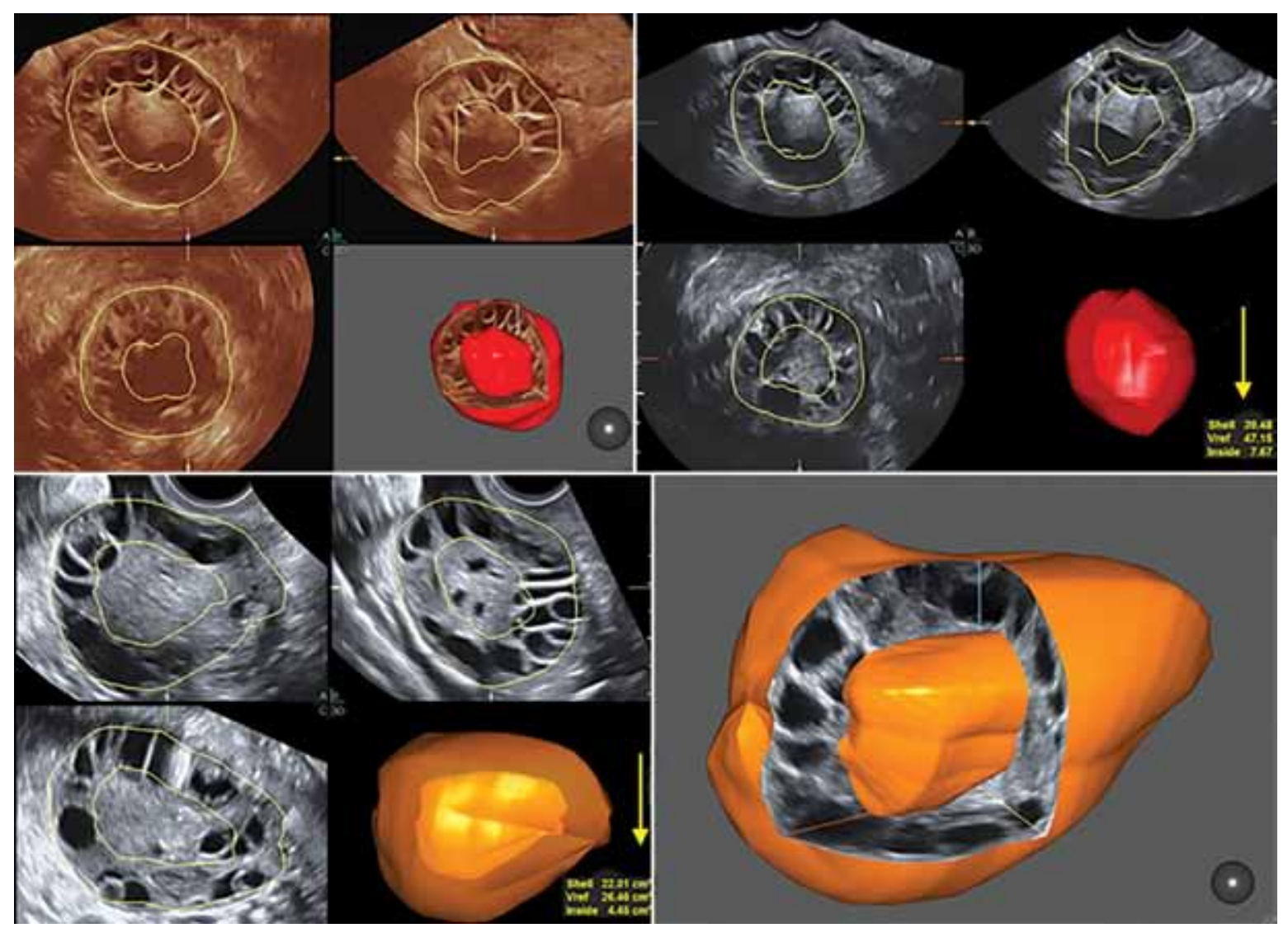

Fig. 15: Double VOCAL and NICHE modes showing the medulla of the ovary in red and orange. Around this structure, numerous small AF. The yellow arrows depict total ovary and medullary volumes. The software calculates the volumes automatically 


\section{Vascularization of the Medulla}

Polycystic ovary syndrome patients shows an enhanced vascularization of the ovarian medulla which remains constant during the menstrual cycle, this feature is not seen in patients having normal hormonal periods which show cyclic changes. ${ }^{38}$

With the pioneering studies focused on Doppler, it was observed that resistance and pulsatility indices were very low in PCOS patients-related to good vascularization-but without changes throughout the cycle, this feature seems to be characteristic of $\mathrm{PCOM}_{1}^{21,38,39}$ although it is not internationally accepted. ${ }^{39}$ This situation might change with the introduction of 3D digital Doppler angiography. ${ }^{21,22}$ This new 3D US mode has allowed observing the following key events in this group of patients:

- A markedly increase in vascularization (Fig. 16).

- Three-dimensional parameters [vascularization (VI), flow (FI), vascularization flow (VFI) indices] significantly higher.

- These features deserve further study to be included as new markers for PCOM.

Several studies have compared these vascular indices between normo and hyperandrogenic women having PCOS. ${ }^{22,41,42}$ The results showed statistically differences as well as a direct relationship between increased flow and hyperandrogenemia:

\begin{tabular}{llll}
\hline & Normoandrogenic & vs & PCOS patients \\
\hline VI $(0-100)$ & $2.79 \%$ & & $3.85 \%$ \\
FI $(0-100)$ & 31.79 & 33.54 \\
VFI $(0-100)$ & 0.85 & 1.27 \\
\hline
\end{tabular}

Besides its enormous interests, we may underline that other several authors remark the lack of uniform data and absence of cut-off values which would still make vascular parameters by Doppler impractical for discriminating between PCOM and normal ovarian morphology. ${ }^{28}$

In our opinion, 3D digital Doppler angiography should be considered as a valuable and potent diagnostic tool.

\section{CONCLUDING REMARKS}

- Recent papers have been published focusing on the redefinition of PCOS, nevertheless, the Rotterdam consensus remains as the most widely accepted across Europe, Asia and Australia and, until a new Consensus, should be still used. .-7,11,29 $^{-1}$

- Initial investigations must exclude other endocrinological abnormalities: thyroid function, prolactin luteinizing (LH) and follicle stimulating hormone (FSH) levels.

- Ovarian US morphology as diagnostic criteria (Rotterdam consensus) plays - in our consideration - a central role, superior to hyperandrogenemia, however, as shown in this review, there is a lack of consensus.

- Indeed, PCOS and control population share a significant overlap in ovarian morphology, and a large proportion (estimates range from 10 to $48 \%$ ) of adolescents who do not have PCOS may have polycysticappearing ovaries. ${ }^{43-45}$

- A PCOS should never be considered in young women until 2 years of establishing normal menstruations. ${ }^{7}$

- There are cases with typical PCOM and hyperandrogenemia but with OV less than $10 \mathrm{cc}$. Ovarian volume

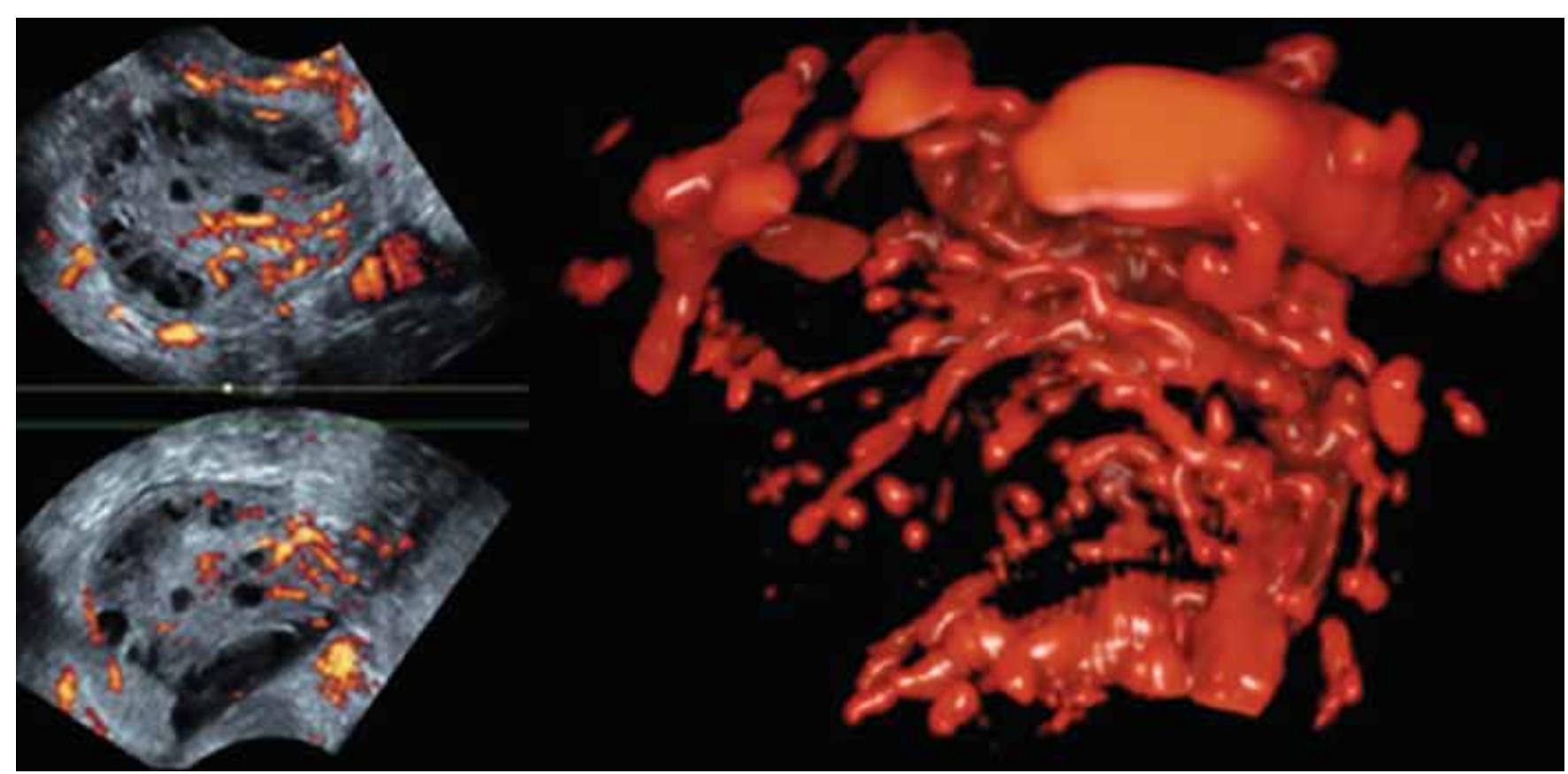

Fig. 16: Vascularization of the medulla in PCOS patients. Note the increased vascular component, gross and long vessels and the absence of changes in flow velocity 
and/or area are not as interesting as published by the Rotterdam consensus.

- The measurement of the medulla, especially if combined with 3D angio-Doppler is a good adjunctive tool in diagnosing PCOS.

- Tomographic ultrasound image (TUI) is only of modest interest for PCOM evaluation. It's neither necessary nor recommended.

- Inversion mode and AVC are much more specific, reliable and recommended than the simple transvaginal $2 \mathrm{D}$ for AF counting.

- 3DUS HDlive ${ }^{\mathrm{TM}}$ and Radiance System Architecture ${ }^{\mathrm{TM}}$ software improve image quality and should be used if available.

- Anovulatory drugs: This medication may interfere with the ultrasonographic appearance of the AF, presumably due to a reduction in testosterone levels, thus, the hormonal and ultrasonography assay are recommended after 3 months of cessation.

- The finding of PCOM in ovulatory women not showing clinical or biochemical androgen excess may be inconsequential. ${ }^{28}$

- Finally, the new 3D US modalities seem to be superior to the standard 2D transvaginal scan, and should be employed when available.

\section{REFERENCES}

1. March WA, Moore VM, Willson KJ, Phillips DI, Norman RJ, Davies MJ. The prevalence of polycystic ovary syndrome in a community sample assessed under contrasting diagnostic criteria. Hum Reprod 2010;25(2):544-551.

2. Conway G, Dewailly D, Diamanti-Kandarakis D, MorrealaEHF, Franks S, Gambineri A, Kelstimur F, Macut D, Micic D, Pasquali $\mathrm{R}$, et al. On behalf of the ESE PCOD Special Interest Group Europ. European survey of diagnosis and management of the polycystic ovary syndrome: results of the ESE PCOS Special Interest Group's Questionnaire. J Endocrinol 2014;171(4):1-29.

3. Hsu Roe A, Dokras A. The diagnosis of polycystic ovary syndrome in adolescents. Rev Obstet Gynecol 2011;4(2):45-51.

4. Zawadski JK, Dunaif A. Diagnostic criteria for polycystic ovary syndrome: towards a rational approach. In: Dunaif A, GivensJR, Haseltine FP, Merriam GR, editors. Polycystic Ovary Syndrome. Boston: Blackwell Scientific Publications; 1992. p. 377-384.

5. The Rotterdam ESHRE/ASRM-Sponsored PCOS Consensus Workshop Group. Revised 2003 consensus on diagnostic criteria and long-term health risks related to polycystic ovary syndrome (PCOS). Human Reprod 2004;19(1):41-47.

6. Ballen AH, Laven JS, Tan SL, Dewailly D. Ultrasound assessment of the polycystic ovary syndrome: International Consensus Definition Human Reprod Update 2003;9(6): 505-514.

7. Boyle J, Teede HJ. Polycystic ovary syndrome. An update. Australian Family Physician 2012;41(10):752-756.

8. Azziz R, Carmina E, Dewailly D, Diamanti-Kandarakis E, Escobar-Morreale HF, Futterweit W, Janssen OE, Legro RS,
Norman RJ, Taylor AE, Witchel SF. Task Force on the Phenotype of the Polycystic Ovary Syndrome of the Androgen Excess and PCOS Society. The Androgen Excess and PCOS Society criteria for the polycystic ovary syndrome: the complete task force report. Fertil Steril 2009;91(2):456-488.

9. Fauser BC, Tarlatzis BC, Rebar RW, Legro RS, Balen AH, Lobo R, Carmina E, Chang J, Yildiz BO, Laven JS. Consensus on women's health aspects of polycystic ovary syndrome (PCOS): The Amsterdam ESHRE/ASRM-Sonsored 3rd PCOS consensus workshop group. Fertil Steril 2012;97(1):28-30.

10. Final Report National Institute of Health. Evidence-based Methodology Workshop on Polycystic Ovary Syndrome December 3-5, 2012. Available at: http://prevention.nih.gov/ workshop/2012/pcos/resourc-es.aspx.

11. Bonilla-Musoles F. Ecogafía vaginal Doppler y Tridimensión. Madrid Panamericana; 2001. ISBN.84-7903-568-8.

12. Dewailly D, Gronier H, Robin G, Leroy M, Pigny P, Duhamenl A, Catteau-Jonard S. Diagnosis of polycystic ovary syndrome (PCOS): revisiting the threshold values of follicle count on ultrasound and of the serum AMH level for the definition of polycystic ovaries. Human Reprod 2011; 26(11):3123-3129.

13. Lujan ME, Jarrett BY, Brooks ED, Reines JK, Peppin AK, Muhn N, Haider E, Pierson RA, Chizen DR. Updated ultrasound criteria for polycystic ovarian syndrome: reliable thresholds for elevated follicle population and ovarian volume. Human Reprod 2013;28(5)1361-1368.

14. Deb S, Campbell BK, Clewes JS, Raine-Fenning NJ. Quantitative analysis of antral follicle number and size: a comparison of two dimensional and automated threedimensional ultrasound techniques. Ultrasound Obstet Gynecol 2010;35(3):354-360.

15. Deb S, Jayaprakasan K, Campbell BK, Clewes JS, Johnson IR, Reine-Fenning NJ. Intraobserver and interobserver reliability of automated antral follicle counts made using threedimensional ultrasound and sono AVC. Ultrasound Obstet Gynecol 2009;33(4):477-483.

16. Jayaprakasan K, Walker KF, Clewes JS, Johnson IR, ReineFenning NJ. The interobserver reliability of off-line antral follicle counts made from stored three-dimensional ultrasound data: a comparative study of different measurement techniques. Ultrasound Obstet Gynecol 2007;29(3):335-341.

17. Jayaprakasan K, Campbell B, Hopkinsson J, Clewes JS, Johnson IR, Reine-Fenning NJ. Establishing the intercycle variability of three-dimensional ultrasonographic predictors of ovarian reserve. Fertil Steril 2008;90(6):2126-2132.

18. Raine-Fenning N, Jayaprakasan K, Clewes J. Automated follicle tracking facilitates standardization and my improve work flow. Ultrasound Obstet Gynecol 2007;30(7):1015-1018.

19. Raine-Fenning N, Campbell BK, Clewes J, Johnson IR. The interobserver reliability of ovarian volume measurement is improved with three-dimensional ultrasound, but dependent upon technique. Ultrasound Med Biol 2003;29(12):1685-1690.

20. Scheffer GJ, Broekmans FJ, Bancsi LF, Habbema JD, Looman CW, TeVelde ER. Quantitative transvaginal two- and three-dimensional sonography of the ovaries: reproducibility of Antral Follicles counts. Ultrasound Obstet Gynecol 2002; 20(3):270-275.

21. Bonilla-Musoles F, Dolz M, Moreno J, Raga F. Reproducción Asistida; Abordaje en la práctica clínica. Madrid: Panamericana; 2008 ISBN 978-84-9835-156-9. 
22. Merce LT, Gomez B, Engels V, Bau S, Bajo JM. Intraobserver and Interobserver reproducibility of ovarian volume, antral follicle count, and vascularity indices obtained with transvaginal 3-dimensional ultrasonography, power Doppler angiography, and the virtual-organ computer-aided analysis imaging program. J Ultrasound Med 2005;24(9):1279-1287.

23. Allemand MC, Tummon IS, Phy JL, Foong SC, Dumesic DA, Session DR. Diagnosis of polycystic ovaries by three-dimensional transvaginal ultrasound. Fertil Steril 2006;85(1):214-219.

24. Kupesic S; Kurjak A, Bjelos D, Vujisic S. Three-dimensional ultrasonographic ovarian measurements and in vitro fertilization outcome are related to age. Fertil Steril 2003;79(1):190-197.

25. Pellicer A, Ardiles G, Neuspiller F, Remohi J, Simon C, BonillaMusoles F. Evaluation of the ovarian reserve in young low responders with normal basal levels of follicle-stimulating hormone using three-dimensional ultrasonography. Fertil Steril 1998;70(4):671-675.

26. Broekmans FJ, Kwee J, Hendriks DJ, Mol BW, Lambalk CB. A systematic review of tests predicting ovarian reserve and IVF outcome. Human Reprod Update 2006;12(6):685-718.

27. Broekmans FJ, De Ziegler D, Howles CM, Gougeon A, Trew G, Olivennes F. The antral follicle count: practical recommendations for better standardization. Fertil Steril 2010;94(3):96-103.

28. Dewailly D, Lujan ME, Carmina E, Cedars MI, Laven J, Norman RJ, Escobar-Morreale HE. Definition and significance of polycystic ovarian morphology: a task force report from the Androgen Excess and Polycystic Ovary Syndrome Society. Human Reprod Update 2014;20(3):334-352.

29. Franks S. Controversy in clinical endocrinology: diagnosis of polycystic ovarian syndrome: in defense of the Rotterdam criteria. J Clin Endocrinol Metab 2006;91(3):786-789.

30. Scheffer GJ; Broekmans FJ, Looman CW, M, Blankenstein FH, De Jong M, Fauser BC, TeVelde TR. The number of antral follicles in normal women with proven fertility is the best reflection of reproductive age. Human Reprod 2003;18(4): 700-706.

31. TeVelde ER, Scheffer GJ, Dorland M, Broekmans FJ, Fauser BC. The variability of female reproductive ageing. Developmental and endocrine aspects of normal ovarian ageing. Human Reprod Update 2002;8(2):141-154.

32. Ng EH, Yeung WS, Fong DY, Ho PC. Effects of age on hormonal and ultrasound markers of ovarian reserve in Chinese women with proven Fertility. Human Reprod 2003; 18(10):2169-2174.

33. Ruess ML, Kline J, Santos R, LevinB, Timor-Tritsch I. Age and the ovarian follicle pool assessed with transvaginal ultrasonography. Am J Obstet Gynecol 1996;174(2): 624-627.

34. Scheffer GJ, Broekmans FJ, Dorland M, Habbema JD, Looman CW, TeVelde TR. Antral follicle counts by transvaginal ultrasonography are related to age in women with proven natural Fertility. Fertil Steril 1999;72(5):845-851.

35. Pavlik EJ, De Priest PD, Gallion HH, Ueland FR, Reedy MB, Kryscio RJ. Ovarian volume related to age. Gynecol Oncol 2000;77(3):410-412.

36. Hendriks DJ, Kwee J, Mol BW, TeVelde ER, Broekmans FJ. Ultrasonography as a tool for the prediction of outcome in IVF patients: a comparative meta-analysis of ovarian volume and antral follicle count. Fertil Steril 2007;87(4):764-775.

37. Corton M, Botella-Carretero JI, Benguria A, Villuendas G, Zaballos A, San Millan JL, Escobar-Morreale HF, Peral B. Differential gene expression profile in omental adipose tissue in women with polycystic ovary syndrome. J Clin Endocrinol Metab 2007;92(1):328-337.

38. Bonilla-Musoles F, Ballester MJ, Carrera JM. Doppler color transvaginal Mason-Salvat Medicina. Madrid 1992. ISBN 84-458-0122-8.

39. Dolz M, Osborne N, Blanes J, Raga F, Abad de Velasco L, Villalobos A, Pellicer A, Bonilla-Musoles F. Polycystic ovarian syndrome: Assessment with color doppler angiography and three-dimensional ultrasonography. J Ultrasound Med 1999;18(4):303-313.

40. Mala YM, Ghosh SB, Tripathi R. Three-dimensional power Doppler imaging in the diagnosis of polycystic ovary syndrome. Int J Gynecol Obstet 2009;105(1):36-38.

41. Lam PM, Johnson IR, Raine-Fenning NJ. Three-dimensional ultrasound features of the polycystic ovary and the effect of different phenotypic expressions on these parameters. Human Reprod 2007;22(12):3116-3123.

42. Pascual MA, Graupera P, Hereter L, Tresserra F, Rodriguez I, Alcazar JL. Assessment of ovarian vascularization in the polycystic ovary by three-dimensional power Doppler Sonography. Gynaecol Endocrinol 2008;24(11):631-636.

43. Bridges NA, Cooke A, Healy MJ, Hindmarsh PC, Brook CG. Standards for ovarian volume in childhood and puberty. Fertil Steril 1993;60(3):456-460.

44. Mortensen M, Rosenfield RL, Littlejohn E. Functional significance of polycystic-size ovaries inhealthy adolescents. J Clin Endocrinol Metab 2006;91(10):3786-3790.

45. Blank SK, Helm KD, McCartney CR, Marshall JC. Polycystic ovary syndrome in adolescence. Ann NY Acad Sci 2008; 1135:76-84. 